There has also been a very constant pattern of cancer over the six decades as regards site and type. This pattern differs considerably from the European pattern in the infrequency of certain types of cancer and the undue frequency of others. This analysis could not have been interpreted in terms of cancer in Western countries, and it is only modern knowledge of the Uganda cancer pattern which enables comparisons to be made. This is particularly the case with the common lymphomatous tumour of children, which has evidently been commonly seen in Uganda for the last 60 years.

There is no evidence that cancer has been uncommon in Uganda since the first days of modern Western medicine, and the stability of the site and type-pattern suggests that it is due to factors embedded in the Uganda African way of life.

This investigation has only been $F$ :ssible because of a very generous research grant made availabie to us over several years by the Trustees of the Anna Fuller Fund. It is a pleasure to acknowledge the constant sympathy and interest of Dr. William Gardner in this and many other cancer problems of the African continent. The Mengo records were most generously made available to us by the authorities at Mengo Hospital and by the kindness of the Superintendent, Dr. W. R. Billington. We are grateful to medical students at Makerere College Medical School for their faithful copying of hundreds of case notes. Mr. R. T. S. Goodchild, Professor J. Knowelden, and Dr. W. R. Doll have assisted us on a number of points. The two London workers are in receipt of a grant from the Medical Research Council of Great Britain.
REFERENCES

Berglas, A. (1957). Cancer: Nature, Cause and Cure. Institut Pasteur. Paris.

Burkitt, D. P. (1958). Brit. F. Surg., 46, 218.

(1962). Postgrad. med. 7., 38, 71.

Cook, A. R. (1901). 7. trop Med. Hyg., 4, 175

- (1946). Uganda Memories. Uganda Society, Kampala.

Davies, A. G. M., and Davies, J. N. P. (1960). Acta Un. int. Cancr., 16, 1320.

Davies, J. N. P. (1956). Bull. Wld Hlth Org., 15, 1041

- (1959). Med. Hist., 3, 47.

— and Owor, R. (1960). E. Afr. med. 7., 37, 249.

- Wilson, B. A., and Knowelden, J. (1962). Lancet, 2, 328.

des Ligneris, M. J. A. (1927). 7. med. Ass. S. Afr., 25, 102 (1936). S. Afr. med. F., 10, 478.

Dodge, O. G. (1962). Acta Un. int. Cancr., 18, 548.

Goodchild, R. T. S. (1947). Brit. med. F., 2, 342.

Higginson, J., and Oettlé, A. G. (1960). 7. Nat. Cancer Inst., 24, 589.

Hoffman, F. L. (1915). Mortality of Cancer Throughout the World. A.M.A. Commemoration Volume, Chicago.

Lambkin, F. J. (1908). In A System of Syphilis, edited by D'A. Power and K. Murphy, vol. 2, p. 329. Longman, London.

Leys, N. (1924). Kenya. 3rd ed. Hogarth Press, London.

Lurie, H. I., and King, B. A. (1962). F. Path. Bact., 83, 576.

Moffat, R. U. (1901). 7. trop. Med. Hyg., 4, 326.

Moorehead, A. (1960). The White Nile. Hamish Hamilton, London.

Nedoon, G. S., and Semambo, Y. B. (1956). E. Afr. med. 7., 33, 189.

O'Conor, G. T., and Davies, J. N. P. (1960). \$. Pediat., 56, 526.

Pedernen, E. (1961). Cancer Registration in Norway: The Incidence of Cancer in Norway, 1953-8. Norwegian Cancer Society, Oslo.

Roscoe, J. (1921). Twenty-five Years in East Africa. Cambridg= Univ. Press.

Willis, R. A. (1960). Pathology of Tumours, 3rd ed. Butterworth, London.

\title{
Routine Radiography for Haemoptysis
}

\author{
GRAHAM POOLE,* M.B., M.R.C.P. ; PETER STRADLING, $†$ M.D., M.R.C.P.
}

Because of its potentially serious significance a history of haemoptysis is an important reason for general practitioners referring patients for chest radiography. Many with this symptom attend " $x$-ray only" sessions and a proportion prove to have abnormal radiographs leading to immediate recall for investigation. A particular problem is posed, however, by that group in which radiographs are normal. Should this one $\boldsymbol{x}$-ray examination suffice? Should such patients have a precautionary repeat radiograph after an interval ? Should they, perhaps, all be more fully investigated ?

For some years it has been the routine of this unit to take the middle course of repeating radiography after an interval of one month in cases where the initial radiograph was negative. It is known that this is the practice at a number of other clinics. It was thought a reasonable procedure because (a) a small lesion might be missed at the first reading, or $(b)$ an early pathological process (particularly carcinoma), being invisible on the first radiograph, might become apparent after the interval. The second reason was thought the more important because observer variation was reduced so far as possible by the double-reading technique employed (Stradling and Johnston, 1955).

Since this routine had been based on an arbitrary decision it was thought desirable to review a sample of such cases to

\footnotetext{
* Assistant Physician and Tutor in Thoracic Medicine, from the Hammersmith Chest Clinic and Department of Medicine, Postgraduate Medical School of London.

† Physician and Lecturer in Respiratory Diseases, from the Hammersmith Chest Clinic and Department of Medicine, Postgraduate Medical School of London.
}

discover what had actually happened to the patients concerned, and, in the light of the findings, to make any appropriate adjustments in the administrative routine of the " $x$-ray only" service to practitioners.

\section{Method}

All patients referred with haemoptysis during 1960 to the " $x$-ray only" session (using a 100-mm. photofluorographic unit) were included in the first part of the survey (first series). Haemoptysis in this context can be defined only in relation to the history provided, and all patients whose referring letter contained such statements as "blood in the sputum" or " coughing up blood" or "haemoptysis" were accepted for the first series, which then totalled 138.

All records of these patients were closely scrutinized. Where a definite diagnosis, adequate to explain the haemoptysis, had been made in relation to the first attendance (group A) no further special follow-up was carried out for the purpose of this investigation. The second category (group B) consisted of patients whose radiographs were negative both initially and on repeat one month later, and who therefore had been discharged: these patients were followed up by a simple questionary during 1963. The majority answered, but where no response was obtained a further follow-up was conducted by a nurse from the clinic visiting the home, seeking information from the doctor originaliy referring the patient, and, finally, by inquiry through the local executive council. A separate, 
third category (group C) was made for disease discovered by the repeat radiography at one month after a normal initial radiograph.

In addition to the above, records relating to 343 patients referred under similar circumstances during 1961 and 1962 were surveyed (second series), but only to discover the proportion falling into the three groups: no follow-up was attempted for these two later years. Combining groups $B$ and $C$ of both the first and second series thus gives a total of three years' evidence from which to decide whether the repeat radiograph at one month was a valuable routine. The total number of patients surveyed in both series was 481 .

\section{Results}

In the first series there were 61 patients in group A, and the diagnoses made are set out in Table I. This group is not further considered in the investigation.

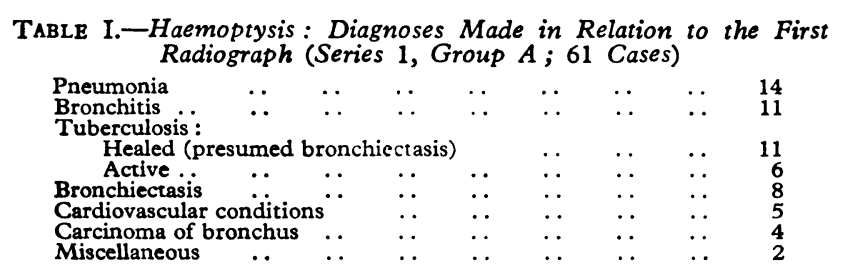

In group B of the first series (Table II) there were 76 patients, of whom only four were not finally traced. Of the remaining 72,66 were found to be fit on follow-up: often a further normal radiograph was available. The details of those who had not remained fit (6) are presented in Table II. There was only one patient in group $\mathrm{C}$ of the first series, and he is discussed under "Conclusions."

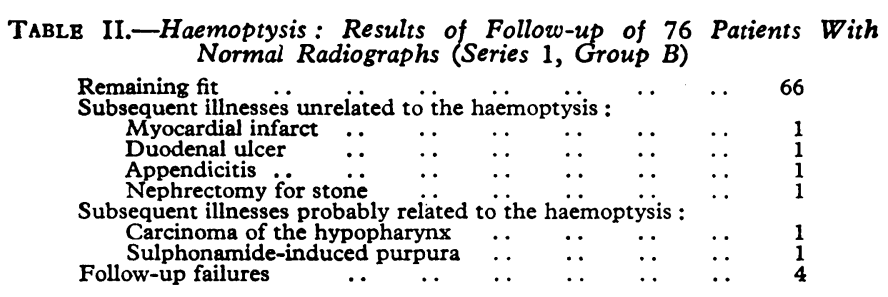

In the second series there were no patients in group $C$; groups A and B contained 139 and 204 patients respectively.

The total number of patients from both series with normal initial radiographs (the combined groups B and C) was 281 . Of these, only that one in group $\mathrm{C}$ of the first series proved abnormal after the interval of one month $(0.35 \%)$.

\section{Conclusions}

The combined A groups, a total of 200 patients, presented no particular problems: the radiographs were abnormal at the first attendance and either led to the confirmation of a known diagnosis or to the immediate recall of the patient for further investigation and consequent diagnosis.

Follow-up of group B in the first series (76), in whom two radiographs at an interval of one month had been reported normal, revealed only two patients whose conditions could even remotely be connected with the originally reported haemoptysis (carcinoma of the hypopharynx and sulphonamide-induced purpura). Immediate full investigation of the patient with hypopharyngeal carcinoma might have led to an earlier diagnosis, but this does not warrant the application of the full and expensive diagnostic machinery to 76 patients, of whom 75 proved fit three years later.

The details of the one case where a repeat radiograph at one month appeared to aid in diagnosis are relevant to the investigation. In this patient the first radiograph was clear, but that repeated at one month showed a pneumonia which had cleared two weeks later. A precautionary radiograph two months later showed further new shadowing, which on investigation proved to be related to a carcinoma. Although it seems likely that the original pneumonia discovered at one month was also related to the carcinoma, it will be appreciated that the discovery of this transient shadowing by a precautionary appointment at one month was fortuitous: a choice of three weeks or six weeks for the repeat would have missed it.

The main revelation of this investigation is the poor yield $(0.35 \%)$ from the 281 routine second radiographs. Therefore it is concluded that this second "precautionary" radiograph after an interval of one month has not been warranted, especially when considered in relation to the amount of work, time, and money spent on it. It should be remembered that all radiographs in this survey were read by two observers: it by no means follows that a similar conclusion would be reached when no such precaution against observer error is employed routinely. When a single reading is relied upon the second radiograph would constitute a valuable precaution against missing abnormalities.

Finally, the high yield of abnormalities (201 out of 481 ; $42 \%$ ) in this group of patients reporting haemoptysis underlines the great significance of this symptom. The availability, for general practitioners, of a routine radiography service at a chest clinic is invaluable, but never more than for patients reporting haemoptysis.

\section{Summary}

A group of 481 patients reporting haemoptysis to their practitioners, and consequently referred to the Hammersmith Chest Clinic for radiography during a three-year period, were studied.

In $201(42 \%)$ patients abnormalities were discovered. Such a rewarding yield stresses the great importance of referring all patients with haemoptysis for radiography.

Only once in 281 cases with normal initial radiographs did a repeat at one month lead to a significant diagnosis $(0.35 \%)$. It is concluded that this second routine radiograph is unnecessary provided the danger of observer variation is minimized by double reading of the first radiograph.

In a smaller series of 138 , covering a one-year period, the individual causes of haemoptysis were assessed in the 61 patients with abnormal radiographs and a follow-up made of the 76 whose radiographs were normal.

We would like to thank all those general practitioners who kindly referred these cases to the clinic.

\section{REFERENCE}

Stradling, P., and Johnston, R. N. (1955). Lancet, 1, 1247. 